ROCZNIKI PSYCHOLOGICZNE/ANNALS OF PSYCHOLOGY

2020, XXIII, 1, 45-61

DOI: http://dx.doi.org/10.18290/rpsych20231-3

NATALIA SIEKIERA ${ }^{\mathrm{a}}$

ARKADIUSZ BIAŁEK ${ }^{\mathrm{b}}$

${ }^{\text {a }}$ Pedagogical University of Cracow, Poland

${ }^{\mathrm{b}}$ Institute of Psychology, Jagiellonian University, Poland

\title{
DEVELOPMENTAL PARTICIPATION: THE NECESSITY OF CULTURAL PERSPECTIVES IN DEVELOPMENTAL PSYCHOLOGY
}

This main aim of this paper is to present some theoretical considerations about the need for a cultural approach in modern developmental psychology. Starting with a critique of the overuniversalisation of developmental research in American psychology, the authors present a paradigm of a relational-developmental system, using the concept of embodiment and a cultural approach in psychological research, in which the principal object of analysis is person-in-action as a culturally inclusive alternative for developmental psychology. This approach will be exemplified by research on development through guided participation and the role of shame in moral and social development in Confucian culture.

Keywords: developmental psychology; cultural psychology; embodiment; guided participation.

\section{INTRODUCTION}

Psychological research seeks to describe and explain how humans perceive, understand, and live in the world. Developmental psychology is a field dedicated

Correspondence concerning this article should be addressed to NATALIA SIEKIERA, Pedagogical University of Cracow, ul. Podchorążych 2, 30-084 Kraków, Poland; email: natalia.siekiera.93 @gmail.com; ORCID: https://orcid.org/0000-0002-1819-8647; ARKADIUSZ BIAŁEK, ORCID: https://orcid.org/0000-0002-9002-4764.

The work of the second author was partially supported by grant 2015/19/B/HS6/01252 titled: "Stability and continuity in the development in theory of mind in middle childhood. Trajectories and predictors of development (Stabilność i ciągłość rozwoju teorii umysłu w średnim dzieciństwie. Trajektorie i predyktory rozwoju)." 
to the comprehension and elucidation of developmental processes and optimization of individual development (Lerner, 2012). Not for the first time is the following question asked: Does modern psychology provide answers about how humans develop and emerge in the world? Concrete answers to this question reveal that there is something "weird" about developmental psychology. In this article, we posit that developmental psychology is often reductionist when explaining developmental processes. We subject the research solutions in use to a critical evaluation and propose a shift in the conception of the scientific paradigm. For this, we propose that cultural psychology is an optimal solution for developmental psychology. We begin by explaining the reasons why modern developmental psychology is lacking a cultural approach. Later, we present the relational paradigm in which Overton's (2008) concept of embodiment demonstrates the important focus of body-in-action. The article draws attention to cultural psychology and its idea of the mutual constitution of the person and culture in his or her development presented in light of Rogoff's theories of person-inaction and guided participation. This approach most fully reflects the importance of culture for development and adjustment with the new paradigm in developmental psychology. A better integration of the cultural approach based on the framework of relational-developmental system theory (Overton, 2006; 2015) with developmental studies can enhance the future of psychological science, both theoretically and empirically.

\section{THE "WEIRD" ISSUE OF DEVELOPMENTAL PSYCHOLOGY RESEARCH}

Arnett (2008) notes that American psychology is not really a human science but rather an indigenous science of American society. An analysis of psychological articles written between 2003 and 2007, 73\% of the authors were affiliated with the United States. 85\% of research samples included English-speaking subjects, mostly Americans, who account for less than 5\% of the world population. Are researchers who publish via APA journals really doing research on human science if it is only focused on 5\% of the population? The big question asked in 2008 is one that people are still grappling with.

The situation in mainstream psychology has not changed much from that time. Cultural meaning-making processes in research are still ignored. A recent analysis by Nielsen et al. (2017) indicates that for high-impact factors, journals of developmental psychology are highly biased towards Western, educated, in- 
dustrialized, rich and democratic populations (i.e., towards WEIRD populations). In all articles $(\mathrm{N}=1,528)$ published in 2015 in Child Development, Developmental Psychology, and Developmental Science, 92\% of all participants were from English-speaking and European countries. Thus, although we assume that we are exploring human development, we are, in effect, exploring cultural specifics. It has become typical for many researchers to treat middle-class European and American groups as optimal. The dominance of this specific cultural group in research on human development makes it more challenging to be aware of the variety of practices paving human development that belong to other cultural communities and cause the development itself to be different (Rogoff, 2003).

In opposition, growing cultural research indicates that many processes that are identified as universal, "basic" psychological processes vary across populations. There is evidence in identified variations in visual perception (Henrich, 2008), spatial cognition (Haun et al., 2006) and many others (Henrich et al., 2010). This variation confirms that much of the psychological domains investigated as universals for human beings are not shared by all cultural communities. It is particularly the case with developmental psychology, where there is growing evidence that different cultural contexts track development in distinct ways from the very beginning of human life during even the most primary actions like motor development (e.g., Nelson et al., 2004; Super, 1976).

The field of cultural psychology and cultural research is widespread and has precursors in developmental psychology (e.g., Lew Vygotsky or Jerome Bruner). Nevertheless, why is the culture perspective still overlooked and underestimated in modern psychology?

Nielsen et al. (2017) noted that, perhaps, cultural approaches in American psychology are not popular because heterogeneous samples are usually limited and depend on a commitment to unique and often substantive temporal and physical resources. Another problem is the need to meet strict standards for publications, which requires extensive university training in scientific design practices in American psychology. Non-Western teams of researchers may be less consistent in their application of Western-centric scientific practices.

A more popular assumption, supporting the lack of heterogeneous practices, is that the national and cultural origins of research do not matter because any human beings could be taken to represent all human beings (Arnett, 2008). On the one hand, this stems from the beginnings of psychological practice and the experimental method in particular. In the experimental method the goal is to design an experiment so that the distracting variables of real life can be stripped away to reveal the essence of a phenomenon. This strategy constitutes the first 
and best psychological method of investigation. On the other hand, it is based on psychology's reductionist philosophy of science, whose pitfalls will be explained in the next section.

A noticeable problem appears in the world of psychology-the cultural approach has been widely known and has become an important field of study in recent decades, but given the monopoly of mainstream APA psychology, it is reflected to a minimal degree.

\section{RELATIONAL-DEVELOPMENTAL SYSTEM THEORY \\ AS A SUGGESTION FOR AN OPTIMAL WAY OF INVESTIGATING HUMAN DEVELOPMENT}

The long-held and dominant paradigm in psychological research is framed by the Cartesian-Split Mechanistic worldview (Overton, 2006). The area of scientific interest is reduced through analysis to the smallest invariant stable component (Prosch, 1964). The Cartesian organism is linear both in behaviour and development. Due to this, the behaviour and development of a particular organism is deterministic and hence, in principle, completely predictable (Overton, 2015). As Marshall (2009) describes: "The Cartesian foundation of this approach has inspired a rising tide of criticism over the last three decades, mainly centered around the problem that the computational mind of cognitivism lacks a brain, a body and a culture" (p. 120). This can lead to a false assumption that knowing the smallest aspects of the behaviour and development of one human being entails our ability to extend our findings onto groups of humans.

Here, one good point is to wonder whether the developmental psychology paradigm in general is inaccurate if it is based on the principle of overuniversalisation and reductionism. The Cartesian science paradigm principle, which assumes that all complexity is simple in the sense that it can always be taken as a purely additive combination of its elements, has not worked well when it comes to developmental psychology. Culture psychology can become integrated with developmental psychology if critical questions are framed using culturally inclusive theories of development in a way that each subfield has something of value to contribute. The main goal is to understand culture and development as complementary and equally necessary (Mistry et al., 2012).

Overton's (2010) relational metatheoretical framework offers a possible path towards understanding human development that rejects the classical Cartesian Split and, in the same place, provides the opportunity to understand conceptual 
contrasts as co-equal, undissociated and complementary (Overton, 2006). Over the past decade it has become a leading perspective in developmental research focused on "process" and dynamic interplay of all developmental systems (Damon, 2015; see: Lerner \& Benson, 2013; Overton et al., 2015). The relational metamodel can provide the new option of implementing cultural psychology in developmental science while considering the importance of sociocultural background and its coaction in human development.

In the relational-developmental system theory, its worldview of relationism rejects simple notions of separable causes. This approach can be contrasted with what Overton (2006) called a "Cartesian worldview" that encourages dichotomies, elevates the explanatory value of proximate mechanisms, disclaims integration and assumes that mental processes are exclusively realised by brain processes. Adopting this leads to the atrophy of the fundamental oppositions, such as cultural vs. individual or culture vs. biology. This conceptual framework offers principles that are relevant to the present argument because it may pave the way to the better use of embodiment together with cultural approach in developmental psychology.

The overarching epistemological principle of the presented theory is holism, in which the identity of objects and events originates from the relational context in which they are embedded. Parts define the whole, but the whole defines the parts as well. For developmental science, this signifies that the analysis of any research object must occur within the context of the parts functioning in the whole (Overton, 2015). Although holism is a central principle for the relationaldevelopmental system theory, it does not always offer a detailed programme for resolving duality problems. However, on this basis, relationism adds specific principles of analysis and synthesis, specifically: (1) Identity of Opposites, where opposites are understood as differentiated polarities of unified inclusive matrix, (2) Opposites of Identity, which emphasise that parts exhibit their unique qualities that distinguish them from other parts of the whole. These characteristics are stable in the holistic system and may be used as standpoints or a level of analysis in empirical inquiry. The last principle is (3) Synthesis of Wholes, which refers to biology, person and sociocultural standpoints as a cast of unity and coacting parts creating biopsychosocial model of an organism (Overton, 2013).

This approach presents a different than mechanistic way of thinking about people and culture. Following a non-Cartesian approach, the idea of mind-brain identity is rejected, which includes mental processes that occur partly within our body and partly outside of it, i.e., in the surrounding space. Following this way of thinking, human-cultural development is a process of creating external infor- 
mation-bearing structures, such as cultural tools, which can be used to facilitate accomplishing developmental tasks. The implication is that culture and psyche "make each other up" (Shweder et al., 2006) and are mutually sustaining. There is no more space to see culture as an independent variable split from the individual. The system that coordinates the nature-nurture polarity is the person in the relational synthesis of biological and sociocultural processes. In these interrelated systems, the cultural approach focuses on differences in the context of psychological functions as complementary to the person and their viewpoint as the focus on psychological functions in the cultural context (Overton, 2013).

\section{CONSTRUCT OF EMBODIMENT AND THE IMPORTANCE OF ACTION IN DEVELOPMENT}

The presented metatheory proposes one construct that can help to operationalise the mutual co-constitution of development and culture in a way that could be empirically analysed. Overton's (2008) concept of embodiment can help in understanding the person and culture as mutually constituted. The integration of developmental systems and relationism has led to an understanding of the developing organism as a co-active process that functions using the reciprocal causality entailed by positive and negative feedback loops (Overton, 2015). In the feedback loop the idea is that the boundaries between the individual and their environment embedded in this developmental system are not clearly determined and are inseparable (Stewart et al., 2010). Overton (2008) presents the individual as a fusion of the biological-cultural world in which embodiment integrates and represents an interpenetrated relationship between biological, cultural and person-centred approaches. The way we conduct ourselves and live in the world is contextualised by our activity through this particular kind of body (Taylor, 1995), where the body, actively engaged in the world, represents the sociocultural perspective.

Embodiment means that "the dynamical body, with its anatomical features and physiological processes acts, and in so doing both constructs and is constructed by the world" (Mistra \& Dutta, 2015, p. 378). But embodiment refers not merely to physical structures, "but the body as a form of lived experience, actively engaged in and with the world of sociocultural and physical objects" (Overton, 2008, p. 3). Recognizing that embodiment bridges and integrates the biological, the psychological and the sociocultural aspects of human functioning 
(Overton, 2008; Mistra \& Dutta, 2015), it is clear that when considering human development culture can no longer be omitted.

Action together with experience is the central construct in the notion of embodiment and provides an elaboration of how the person, biology and culture work in harmony. Overton (2008) claims that all development occurs through experience that is represented by the action of a person immersed in sociocultural and environmental standpoints. Likewise, the concept of person-inactivity (Rogoff, 2003) as a unit of investigation is already applied in some approaches of cultural psychology. With the withdrawal of the reductionist Cartesian approach, it can be the best new/old way to properly investigate human development. The first function of action makes biology, the person and the sociocultural world incorporated into a relational matrix through participation in the transformation of the objective physical and social world into a world of lived experience. The second function of action (which is instrumental) stresses the inseparability of the person and culture in the developmental process. The embodied action is determined as the fundamental microscopic processes of developmental change. In this case, the person acts in a social world to achieve certain goals. Depending on the accomplishment of the desired goal, a positive or negative feedback loop is generated. The effect of the feedback loops existing between embodied acts and the sociocultural world results in changes in the person's functioning and hence development. The construct of embodiment may lead, then, to a better understanding of synthesis and, in fact, to acknowledgment of the inseparability of the person, biology and culture. Moreover, it may facilitate the operationalization of mutually constitutive relations between person-inactivity and context cultivated by a cultural approach in psychology (Mistry \& Dutta, 2015).

From the beginning, the cultural perspective portrays the developmental process as one that occurs through an individual's participation in culturally situated activities and contexts and includes an appropriation of mental tools and symbolic systems (Cole, 1998; Rogoff, 2003). This notion of developmental change and its path is also discussed by sociohistorical-cultural psychologists. For example, Rogoff (2003) highlights individual participation and activity in the sociocultural world as a nexus of developmental transition. She views development as the process of transformation in one's participation in sociocultural activities of their social environment, which, in turn, contributes to changes in the community across generations. In Rogoff's article (2018), the relation between embodiment and culture is even more visible by focusing attention on the importance of children's lived experience for the proper understanding of development. Develop- 
ment should be studied with consideration of children's participation as an active agent in the setting of theirs lives. Along with the relationism worldview in this cultural approach, the culture, context and person are all inseparable. Person-inactivity therefore seems to be a suitable unit of analysis in which a person and their context are mutually constitutive. The integration of relational developmental systems and cultural perspective can be fully achieved if the context is recognised as being cultural in nature, where context will always be interpreted through the meaning-making process and mediational means that are cultural by nature, and embodiment can be a supportive heuristic to research investigation.

\section{INSEPARABILITY \\ OF PERSON-IN-ACTION AND CULTURE}

The conceptual solution introduced in the paper above involves identification of the inseparability of the person and cultural levels of functioning. It also adopts a joint focus on activity as the basic unit of analysis and a concept that embodied action can be a heuristic for an integrative analysis of the person and culture. It this approach, attention will be embedded in the conceptual frameworks in cultural psychology, which shares the position of mutual constitution of the person and the environment on the developmental path.

The key to understanding developmental trajectories of the human species in a proper way lies in understanding how we create and navigate through culture. In comparison with other species, mankind can be called not only social or cultural but also "ultra-cultural." Compared to non-human cultures, our culture is cumulative, leading us to generate a sophisticated repertoire of behaviours; it is variable across communities and shaped through social interaction and social learning (Pagel, 2012).

Cultural and cross-cultural psychology are two approaches of the psychology of culture, which have arisen from difference in operationalization of culture and the focus of investigation (Greenfield, 2000). Principles underlying cultural psychology are based on Counter-Enlightenment approach, in which humans are viewed as collectively constituting their society and culture through their shared mentality, and the relation between culture and person is based on mutual constitution. Otherwise, cross-cultural psychology is based on an Enlightenment view of humans as equal in principle and equally capable to reason. Because culture is taken to be an independent variable in research, we can study interactions between culture and person (Kashima \& Gelfand, 2011). The second approach to 
the study of humans adapted a linear model of causality, where culture influences or shapes behaviour treated as the dependent variable (Berry, 1980). Following the opinion of Shweder (1990) — who started the critique of cross-cultural approaches in psychology - about culture and psyche as mutually constitutive, culture is viewed as meanings embodied in cultural artefacts. The person and the culture cannot be understood in isolation of one another. Meaning as well as context are theoretically represented as parts of the psychological system (Fung, 2011). Cultural contexts are maintained and identified through particular ways of acting and interacting in the episodes of everyday life. In this view, culture and behaviour, or culture and mind, are indistinguishable, whereby culture is viewed as not existing outside the person and should not be considered as an independent variable. Based on this assumption, cultural psychology attempts to articulate and analyse the substantive aspects of culture, seeing it as an emergent property of individuals interacting with and changing their environment (Kim, 2001). When it comes to developmental research, cultural psychology places attention on studying diachronic processes of socialisation that constitute cultural learning and apprenticeship (Rogoff, 1990; Tomasello, 2009). These processes can be conceptualised, then, as ones that create a cultural adult, who, in turn, participates in the process of socialisation of the next generations of his or her community (Keller \& Greenfield, 2000). The foundations on which the cultural approach was formed established the view of cultural psychology presented in the article.

Cultural psychologists view developing selves as becoming active cultural participants. Theoretical frameworks (Rogoff, 2003; Super \& Harkness, 2002) that perceive children as active participants in their environment share the basic position of development being a process that occurs in a network of interpersonal relationships and materialises through interactions with other, usually more mature, members of their community. In this approach, children may even acquire knowledge and practice through observation or eavesdropping during participation in events taking place at home and in the community (Fung, 2011). Emphasis is placed especially on mundane activities, which create daily routines involving children, and they are perceived as the most important influence that shapes a child's cultural developmental pathway (Weisner, 1998). These cultural theories place greater stress on the process of becoming rather than focusing on developmental outcomes.

The basis constituting theories of cultural development comes from Vygotsky's (1978) cultural history theory, in which individual development must be interpreted and cannot be understood without sociocultural and historical 
contexts. In this case the efforts of the individual are not separate from the activities and social institutions in which they engage. According to this theory, the zone of proximal development is the space of interaction between a child and her more skilled partners, in which by using tools for thinking provided by culture children learn how to think independently and transform the cultural tools of thought for their own purposes.

The sociocultural perspective underlines the idea that people contribute to the creation of cultural processes, and these processes contribute to the creation of people. Thus, the mutual constitution between individual and culture can be observed (Cole, 1998; Rogoff, 2003; also see: Keller, 2007).

Considering the use of activity as the unit of analysis, socio-historicalcultural psychologists have created the mutually constitutive nature of person and context, emphasising the idea of person-in-activity as the basic unit in developmental studies (Rogoff, 2003). In this approach, the cultural scientists believe that people develop as they participate in and contribute to cultural activities and that they themselves develop with the involvement of people in successive generations. The development can then be studied via transformation of participation in sociocultural activities. Rogoff $(2003,2008)$ proposes an interesting approach that involves observing development by analysing sociocultural activity through apprenticeship, guided participation and participatory appropriation. Analysing certain activities or events enables, like with the embodiment approach (Overton, 2008), a reformulation of the relationship between the person and their cultural environment in which each is inherently involved in the others' definition.

\section{CULTURAL THEORETICAL PERSPECTIVE \\ OF THE ANALYSIS OF DEVELOPMENT THROUGH PARTICIPATION IN COMMUNITY}

In this section, we will focus more attention on the shift away from the mainstream paradigm - in which culture and the individual are separate - to cultural considerations regarding development proposed by Rogoff $(2003,2016)$. Her idea of development through participation in cultural communities is based on a transactional worldview which together with relationism share the principle of a holistic unit of analysis and the relation of culture and person as being mutual. This is an example of a research approach that could be situated under the bigger metatheoretical framework of relational developmental systems. 
To begin, it will be helpful to explain what cultural community is. For the purpose of this discourse, it can be defined as a group of people who have common and continuing organisations, values and practices. Thinking about the cultural community is supposed to help one focus more on people's participation in cultural processes that form traditions and practices of a particular community, which transcend the individual involved as one generation replaces another (Rogoff, 2003). People in so-called cultural communities create coordinated organisations that make them act in complementary roles, which fit together rather than functioning individually. Through generations, they shape cultural practices and build the community on what they have inherited.

In so-called cultural communities, a person's development can be observed on three planes of analysis: personal, interpersonal, and cultural-institutional. These planes reflect concepts of apprenticeship, guided participation, and participatory appropriation (Rogoff, 1990; Rogoff, 1993). These concepts constitute activities and are useful in viewing the activities and person-in-action as the most important parts of the developmental processes of the cultural individual.

Guided participation applies to the interpersonal plane of socio-cultural analysis. It is a concept that refers to the process of mutual involvement between members of a community as they communicate and coordinate during participation in culturally valued activities (Rogoff \& Gardner, 1984). This notion is central in understanding cultural learning and development as a process of changing participation in community activities. It involves focusing on interpersonal displays that constitute participation in social events. "Guidance" refers to participation that involves the direction offered by cultural values as well as social partners. It goes beyond interactions, which are intended to be only instructional. From the perspective of child development, it includes face-to-face interactions as well as side-by-side and distal arrangements in which children participate. "Participation" in guided participation is understood as any hands-on undertaken action that is the same as observation of other members of the community (Rogoff, 2003). The entire concept provides us with an outlook on interpersonal co-actions as they fit in sociocultural processes and provide information on human learning and development. The basic area of analysis is made up of everyday events in which children socially participate and engage with others and cultural tools collaboratively managed by themselves and by others.

Apprenticeship in socio-historical-cultural theories (Bruner, 1983; Dewey, 1916) refers to the advancement of skills and cultural scripts by newcomers through participation with others. It is a broad plane that not only analyses expert-novice dyads but also focuses on institutional structures and cultural tools. 
The element that distinguishes apprenticeship from guided participation is an emphasis on the relation of the practices and activities to institutions of the community in which participants are involved (Rogoff, 2008).

The third nucleus of the cultural analysis of development is participatory appropriation. Rogoff explains this term as a way in which an individual, by participating in one activity, becomes better prepared for related activities and how the individual creates their own understanding of the activity itself. It is a personal process in which individuals engage in cultural activities rather than what occurs in guided participation on the interpersonal plane of analysis. While "appropriation" can itself be understood simply as an "internalization," the cultural perspective emphasises that in "participatory appropriation," the person is a part of the activity and cannot internalise social events as something separate from themselves. The cultural and interpersonal influences are not viewed as static external factors that impact development. Appropriation occurs in the process of participation, which requires creative endeavours of people to contribute to the concrete social activities (Rogoff, 2008). Here, it can be noticed that development itself is a dynamic process of social participation in communities, where no specific and strict boundaries exist and where the main focus is placed on human activity. For this reason, it can be observed that the approach presented by Rogoff connects with the principles of a broad metatheory of relational-developmental system and could be successfully incorporated in the developmental psychology of nonCartesian worldviews.

\section{EXEMPLIFICATION \\ OF THE THEORETICAL FRAMEWORK}

In the last section, we present two examples from multiple cultural studies that support the theoretical framework. The most comprehensively investigated case is The Girl Scout Cookie Sales (Rogoff et al., 2002), in which researchers showed the mutual contribution of individual, interpersonal and cultural foci of analysis as constituting aspects of cognitive activities. Their analysis permits an investigation of one plane as always maintaining the key aspects of the other planes. Specifically, the planes are never independent of one another, paying attention that every standpoint of investigation is interrelated with the others. Using functional pattern analysis, Rogoff \& Gauvain (1986) were able to discern patterns across the cases without disrupting the sensitivity of the phenomenon that characterised ethnographic work. In short, they noticed that the distributed 
planning for actions and product delivery during Girl Scout Cookie Sales and any other cognitive tasks connected with the job were not completed by a single girl acting in separation from other people and the organisation. In this case, the girl selling the cookies was actively engaged in a social collaborating structure that helped her and her friends to perform the tasks and use some cultural tools to facilitate the process. The analysis of aspects of planning to be remembered by the Girl Scouts showed that cognitive development processes occurred through participation in sociocultural activities in which they were guided by other members of the community. This process provides an illustration how development takes place through guided participation in everyday practice and needs to be studied in ecology considering local practices. Such research illustrates how we can try to use the idea of person-in-action and guided participation in a study of cognitive processes involving culture. Together with embodiment seen as the personal level of analysis, it can provide a holistic view of the issue at hand. In the above example, it was possible to base a cultural study on the relational-development system theory approach (even if it was not explicit in this study) as both describe development as a process investigated from interrelated standpoints.

Another study that contributed to the claim of cultural importance in social cognitive development is a longitudinal study of spontaneous interactions in families of preschoolers in Taiwan dedicated to the investigation of shame (Fung, 1999). Although traditional divisions between shame and guilt cultures (Benedict, 1946) is no longer valid (Wong \& Tsai, 2007), shame is highly elaborated and hypercognized emotion in Chinese culture (Fung, 2006). The silence of shame in Confucian traditions is reflected in its powerful association with moral socialization and in regarding shame as closely related to the traditional virtues of China (i.e., righteousness, benevolence, propriety, and wisdom; Fung, 1999; 2006). In the indigenous, emic, qualitative and longitudinal study focused around interviews with caregivers and observation of spontaneous home interactions between caregivers and children, Fung (1999) revealed that the concept of shame is in this particular cultural circle present by age two and a half and has moral, prosocial and motivational implications for development. Taiwanese caregivers-in reaction to children's transgressions - apply a variety of practices to arouse shame feelings within the child and treat these episodes as opportunities for education and moral lessons (Fung, 1999; 2011). By arousing shame in reconstructing, re-living and reinterpreting the child's recent transgression, caregivers (re)establish norms of conduct. For example, in reaction to the misbehaviour of a three-year old son, his mother said: "You're [a] child who doesn't obey 
rules," and when the boy started to cry, she added: "Let him cry; it doesn't matter" and "Look how ugly your crying will be on the tape" (Fung, 1999, p. 193). Thus, Chinese cultural contexts may be understood as shame-socialized cultures where its members are explicitly socialized and expected to be sensitive to shame and it is understood as a moral virtue and means of social cohesion (Fung, 2006). It is considered to be part of parents' responsibility to teach shame in a balanced, careful and supportive way, and thus prepare the child for social life in a group. Moreover, Fung's (1999) study emphasized the sociocultural aspect of emotional development showing that shame is taught through socialization and in the context of, like Rogoff would say, guided participation.

This cultural study, which is an example of scrupulous analysis of everyday practice, deep interviews and consideration for a broader social context of moral training, discovered categories of development of emotions that are culturally specific. This is another example of the importance of the cultural point of view and the aspects of interactions in the study of cognitive development, showing that emotions are not only internal cognitive processes, but are lived experiences embedded in cultural structures full of unique meanings.

\section{CONCLUSION}

Mainstream psychology underestimates the value of cultural contexts, paying little attention to its co-constitution with an individual's development (Nielsen et al., 2017). In this article, we placed emphasis on a finer cultivation of the cultural approach in developmental psychology to make it more solid and tangible. The proposition was that the use of a non-Cartesian scientific framework, its construct of embodiment (Overton, 2008), and switching cultural researchers' attention from the person and their inner characteristics to person-in-action (Rogoff, 2003) - can all give us a better understanding of the person and culture as mutually constitutive. For developmental science, the theoretical framework presented in this article provides broad possibilities for studying culture and human development, for example, to explore socialisation and cultural influences in the very first stages of human life. A theoretical framework of the relationaldevelopmental system theory can facilitate a coherent integration of cultural approaches with others that exist, helping to connect the areas of the brain, body and culture as equally important in one research method. The importance of the outside world and the cultural and social surroundings of the person immersed in their interpersonal networks cultivated under this approach is a significant aspect 
that carries valuable information. Unfortunately, in lab research this information is constantly omitted. Notwithstanding, the task of combining the presented frameworks is challenging and requires extensive knowledge and comprehensive methodology. In-depth studies combining the proposed approaches would bring us closer to finding important and novel data and explanations for how people perceive, understand, and live in the world, enriching the scientific field of psychology. Therefore, we believe that incorporating culture as a mutual constitution of the embodied person is a perspective worth challenging in psychology.

\section{REFERENCES}

Arnett, J. J. (2008). The neglected 95\%: Why American psychology needs to become less American. American Psychologist, 63(7), 602-614. https://doi.org/10.1037/0003-066X.63.7.602

Benedict, R. (1946). The Chrysanthemum and the Sword: Patterns of Japanese Culture. New American Library.

Berry, J. W. (1980). Introduction to methodology. In H. C. Triandis \& J. W. Berry (Eds.), Handbook of cross-cultural psychology (Vol. 2, pp. 1-28). Allyn and Bacon.

Cole, M. (1998). Cultural psychology: A once and future discipline. Harvard University Press.

Damon, W. (2015). Foreword to the Handbook of Child Psychology and Developmental Science (7th ed.). In W. F. Overton \& P. Molenaar (Eds.), Handbook of child psychology and developmental science (Vol. 1, pp. VII-XIII). John Wiley \& Sons.

Dewey, J. (1916). Democracy and education: An introduction to the philosophy of education. Macmillan.

Fung, H. (1999). Becoming a moral child: The socialization of shame among young Chinese children. Ethos, 27(2), 180-209. https://doi.org/10.1525/eth.1999.27.2.180

Fung, H. (2006). Affect and early moral socialization: Some insights and contributions from indigenous psychological studies in Taiwan. In U. Kim, K.-S. Yang, \& K.-K. Hwang (Eds.), Indigenous and Cultural Psychology. Understanding People in Context (pp. 175-196). Springer. https://doi.org/10.1007/0-387-28662-4_8

Fung, H. (2011). Cultural psychological perspective on social development in childhood. In P. K. Smith \& C. K. Hart (Eds.), The Wiley-Blackwell handbook of childhood social development (pp. 100-118). Blackwell Publishing.

Greenfield, P. M. (2000). Three approaches to the psychology of culture: Where do they come from? Where can they go? Asian Journal of Social Psychology, 3(3), 223-240.

Haun, D. B., Call, J., Janzen, G., \& Levinson, S. C. (2006). Evolutionary psychology of spatial representations in the hominidae. Current Biology, 16(17), 1736-1740. https://doi.org/10. 1016/j.cub.2006.07.049

Henrich, J. (2008). A cultural species. In M. Brown (Ed.), Explaining culture scientifically (pp. 184-210). University of Washington Press.

Henrich, J., Heine, S. J., \& Norenzayan, A. (2010). The weirdest people in the world? Behavioral and brain sciences, 33(2-3), 61-83. https://doi.org/10.1017/S0140525X0999152X

Keller, H., \& Greenfield, P. M. (2000). History and future of development in cross-cultural psychology. Journal of Cross-Cultural Psychology, 31(1), 52-62. https://doi.org/10.1177/ 0022022100031001005 
Keller, H. (2007). Cultures of infancy. Lawrence Erlbaum Associates. https:/doi.org/10.4324/ 9780203936771

Kashima, Y., \& Gelfand, M. J. (2012). A history of culture in psychology. In A. W. Kruglanski \& W. Stroebe (Eds.), Handbook of the history of social psychology. Psychology Press. http://dx.doi.org/10.4324/9780203808498.ch23

Kim, U. (2001). Culture, science and indigenous psychologies: An integrated analysis. In D. Matsumoto (Ed.), Handbook of culture and psychology (pp. 51-76). Oxford: Oxford University Press.

Lakatos, I. (1978). The methodology of scientific research programmes: Philosophical papers (Vol. 1). Cambridge University Press. https://doi.org/10.1017/CBO9780511621123

Lerner, R. M. (2012). Essay review: Developmental science: Past, present, and future. International Journal of Developmental Science, 6, 29-36. https://doi.org/10.3233/DEV2012-12102

Lerner, R. M., \& Benson, J. B. (2013). Embodiment and epigenesis: Theoretical and methodological issues in understanding the role of biology within the relational developmental: Part A, philosophical, theoretical, and biological dimensions. Academic Press.

Marshall, P. J. (2009). Neuroscience, embodiment, and development. In W. F. Overton, P. C. M. Molenaar, \& R. M., Lerner (Eds.), Handbook of child psychology and developmental science (Vol. 1, pp. 244-283). Wiley.

Mistry, J., Contreras, M., \& Dutta, R. (2012). Culture and child development. In R. M. Lerner, M. A. Easterbrooks, \& J. Mistry (Eds.), Developmental psychology. Comprehensive handbook of psychology (Vol. 6, pp. 265-285). Wiley.

Mistry, J., \& Dutta, R. (2015). Human development and culture. In W. F. Overton \& P. Molenaar (Eds.), Handbook of child psychology and developmental science (Vol. 1, pp. 369-406). John Wiley \& Sons. https://doi.org/10.1002/9781118963418.childpsy110

Nelson, E. A. S., Yu, L. M., Wong, D., Wong, H. Y. E., \& Yim, L. (2004). Rolling over in infants: age, ethnicity, and cultural differences. Developmental Medicine \& Child Neurology, 46(10), 706-709. https://doi.org/10.1111/j.1469-8749.2004.tb00985.x

Nielsen, M., Haun, D., Kärtner, J., \& Legare, C. H. (2017). The persistent sampling bias in developmental psychology: A call to action. Journal of Experimental Child Psychology, 162, 31-38. https://doi.org/10.1016/j.jecp.2017.04.017

Overton, W. F. (2006). Developmental psychology: Philosophy, concepts, methodology. In R. M. Lerner (Ed.), Theoretical models of human development. Handbook of child psychology (6th ed., Vol. 1, pp. 18-88). Wiley.

Overton, W. F. (2008). Embodiment from a relational perspective. In W. F. Overton, U. Mueller, \& J. Newman (Eds.), Developmental perspectives on embodiment and consciousness (pp. 1-18). Erlbaum.

Overton, W. F. (2010). Life-span development: Concepts and issues. In W. F. Overton (Ed.), Cognition, biology, and methods across the lifespan. The handbook of life-span development (Vol. 1, pp. 1-29). Wiley.

Overton, W. F. (2013). Relationism and relational developmental systems: a paradigm for developmental science in the post-Cartesian era. Advances in child development and behavior, 44, 21-64. https://doi.org/10.1016/B978-0-12-397947-6.00002-7

Overton, W. F. (2015). Processes, relations, and relational-developmental-system. In W. F. Overton \& P. Molenaar (Eds.), Handbook of child psychology and developmental science (Vol. 1, pp. 9-63). John Wiley \& Sons. https://doi.org/10.1002/9781118963418.childpsy102 
Overton, W. F., Lerner, R. M., \& Molenaar, P. (2015). Handbook of child psychology and developmental science: Vol. 1. Theory and Method. John Wiley \& Sons.

Pagel, M. (2012). Wired for culture: origins of the human social mind. WW Norton \& Company.

Prosch, H. (1964). The genesis of twentieth century philosophy. Doubleday.

Rogoff, B. (1990). Apprenticeships in thinking. Cognitive development in social context. Oxford University Press.

Rogoff, B. (1993). Children's guided participation and participatory appropriation in sociocultural activity. In R. Wozniak \& K. Fischer (Eds.), Development in context: Acting and thinking in specific environments (pp. 121-153). Psychology Press.

Rogoff, B. (2003). The cultural nature of human development. Oxford University Press.

Rogoff, B. (2008). Observing sociocultural activity on three planes: Participatory appropriation, guided participation, and apprenticeship. Pedagogy and practice: Culture and identities, 58-74. https://doi.org/10.1017/CBO9781139174299.008

Rogoff, B., \& Gardner, W. (1984). Adult guidance of cognitive development. In B. Rogoff \& J. Lave (Eds.), Everyday cognition: Its development in social context (pp. 95-116). Harvard University Press.

Rogoff, B., Mistry, J., Göncü, A., Mosier, C., Chavajay, P., \& Heath, S. (1993). Guided participation in cultural activity by toddlers and caregivers. Monographs of the Society for Research in Child Development, 58(8), 1-179. https://doi.org/10.2307/1166109

Rogoff, B., Topping, K., Baker-Sennett, J., \& Lacasa, P. (2002). Mutual contributions of individuals, partners, and institutions: Planning to remember in Girl Scout cookie sales. Social Development, 11(2), 266-289. https://doi.org/10.1111/1467-9507.00198

Rogoff, B., Dahl, A., \& Callanan, M. (2018). The importance of understanding children's lived experience. Developmental Review, 50, 5-15. http://dx.doi.org/10.1016/j.dr.2018.05.006

Shweder, R. A., Goodnow, J., Hatano, G., LeVine, R. A., Markus, H., \& Miller, P. (2006). The cultural psychology of development: One mind many mentalities. In M. R. Lerner, \& W. Damon (Eds.), Theoretical models of human development. Handbook of child psychology (6th ed., Vol. 1, pp. 716-792). John Wiley \& Sons.

Stewart, J., Gapenne, O., \& Di Paolo, E. (2010). Enaction: Towards a new paradigm for cognitive science. MIT Press.

Super, C. M., \& Harkness, S. (2002). Culture structures the environment for development. Human development, 45(4), 270-274. http://dx.doi.org/10.1159/000064988

Super, C. M. (1976). Environmental effects on motor development: The case of 'African infant precocity'. Developmental Medicine \& Child Neurology, 18(5), 561-567. http://dx.doi.org/ 10.1111/j.1469-8749.1976.tb04202.x

Taylor, C. (1995). Philosophical arguments. Harvard University Press.

Tomasello, M. (2009). The cultural origins of human cognition. Harvard University Press.

Vygotsky, L. S. (1978). Mind in society: The development of higher mental process. Harvard University Press.

Wong, Y., \& Tsai, J. (2007). Cultural models of shame and guilt. In J. L. Tracy, R. W. Robins, \& J. P. Tangney (Eds.), The self-conscious emotions: Theory and research (pp. 209-223). Guilford Press.

Wiesner, T. S. (1998). Human development, child well-being, and the cultural project of development. New Directions for Child and Adolescent Development, 80, 69-85. http://dx.doi.org/10.1002/cd.23219988006 